\title{
Prevalence and burden of chronic bronchitis symptoms: results from the BOLD study
}

\author{
Filip Mejza ${ }^{1}$, Louisa Gnatiuc ${ }^{2}$, A. Sonia Buist ${ }^{3}$, William M. Vollmer ${ }^{4}$, \\ Bernd Lamprecht ${ }^{5,6}$, Daniel O. Obaseki ${ }^{7}$, Pawel Nastalek ${ }^{1}$, \\ Ewa Nizankowska-Mogilnicka ${ }^{1}$ and Peter G.J. Burney ${ }^{2}$ for the BOLD \\ collaborators $^{8}$
}

Affiliations: ${ }^{1}$ Il Dept of Internal Medicine, Jagiellonian University Medical College, Krakow, Poland. ${ }^{2}$ Dept of Respiratory Epidemiology, Occupational Medicine and Public Health, Imperial College London, London, UK. ${ }^{3}$ Pulmonary and Critical Care Medicine, Oregon Health and Science University, Portland, OR, USA. ${ }^{4}$ Center for Health Research, Kaiser Permanente, Portland, OR, USA. ${ }^{5}$ Dept of Pulmonary Medicine, Kepler University Hospital, Linz, Austria. ${ }^{6}$ Faculty of Medicine, Johannes Kepler University, Linz, Austria. ${ }^{7}$ Dept of Medicine, Obafemi Awolowo University, Ile-Ife, Nigeria. ${ }^{8} \mathrm{~A}$ full list of the BOLD collaborators can be found in the Acknowledgements section.

Correspondence: Filip Mejza, II Dept of Internal Medicine, Jagiellonian University, Medical College, UL. Skawinska 8, 31-066, Krakow, Poland. E-mail: filipmejzaQhotmail.com

@ERSpublications

Chronic bronchitis symptoms are associated with significant burden regardless of the presence of airflow obstruction http://ow.ly/kP9P30eFELK

Cite this article as: Mejza F, Gnatiuc L, Buist AS, et al. Prevalence and burden of chronic bronchitis symptoms: results from the BOLD study. Eur Respir J 2017; 50: 1700621 [https://doi.org/10.1183/ 13993003.00621-2017].

ABSTRACT We studied the prevalence, burden and potential risk factors for chronic bronchitis symptoms in the Burden of Obstructive Lung Disease study.

Representative population-based samples of adults aged $\geqslant 40$ years were selected in participating sites. Participants completed questionnaires and spirometry. Chronic bronchitis symptoms were defined as chronic cough and phlegm on most days for $\geqslant 3$ months each year for $\geqslant 2$ years.

Data from 24855 subjects from 33 sites in 29 countries were analysed. There were significant differences in the prevalence of self-reported symptoms meeting our definition of chronic bronchitis across sites, from $10.8 \%$ in Lexington (KY, USA), to $0 \%$ in Ile-Ife (Nigeria) and Blantyre (Malawi). Older age, less education, current smoking, occupational exposure to fumes, self-reported diagnosis of asthma or lung cancer and family history of chronic lung disease were all associated with increased risk of chronic bronchitis. Chronic bronchitis symptoms were associated with worse lung function, more dyspnoea, increased risk of respiratory exacerbations and reduced quality of life, independent of the presence of other lung diseases.

The prevalence of chronic bronchitis symptoms varied widely across the studied sites. Chronic bronchitis symptoms were associated with significant burden both in individuals with chronic airflow obstruction and those with normal lung function.

Received: March 242017 | Accepted after revision: Aug 102017

Support statement: the list of the BOLD study sponsors can be found at the BOLD website (www.boldstudy.org/ sponsors.html). The sponsors had no role in the study design, data collection, data analysis, data interpretation or writing of the report.

Conflict of interest: None declared.

Copyright @ERS 2017. This version is distributed under the terms of the Creative Commons Attribution Licence 4.0. 


\section{Introduction}

Chronic bronchitis is defined epidemiologically as cough and sputum production for $\geqslant 3$ months in each of least two consecutive years [1]. It affects about a third of patients with chronic obstructive pulmonary disease (COPD), but also occurs in individuals with normal lung function, with prevalence estimates varying widely both in population-based studies (2.6-16\%) [2-7] and among COPD patients (7.4-53\%) [8-10]. Presence of chronic bronchitis symptoms correlates with faster forced expiratory volume in $1 \mathrm{~s}$ (FEV1) decline and increased risk of death in most [11-15], but not all $[16,17]$ published studies. In addition, it is associated with worse health status in affected subjects $[4,9,10]$. Reported risk factors for chronic bronchitis include tobacco smoke, indoor and outdoor air pollution and occupational exposures [18-21].

Although chronic bronchitis symptoms are commonly reported, data on their prevalence across countries and burden in affected individuals, especially in those with normal lung function, are limited [2-4]. The Burden of Obstructive Lung Disease (BOLD) study is an international, cross-sectional study assessing the prevalence and burden of COPD across different parts of the world [22]. In this article we report data from the BOLD study on the prevalence, burden and potential risk factors of chronic bronchitis symptoms.

\section{Material and methods}

The methods used in the BOLD study are described in detail elsewhere [22]. In brief, representative population-based samples of adults aged $\geqslant 40$ years were selected randomly in participating centres. Participants who had provided written informed consent completed a detailed questionnaire and pre- and post-bronchodilator spirometry, administered by trained and certified staff. The questionnaires were translated into languages used in local sites, back-translated and verified. Spirometry was performed using the Easy-One spirometer (ndd Medical Technologies, Zurich, Switzerland) before and $15 \mathrm{~min}$ after administration of bronchodilator $(200 \mu \mathrm{g}$ salbutamol). All spirograms were centrally assessed for quality, and only measurements of appropriate quality (based on the American Thoracic Society/European Respiratory Society criteria) were used for analyses [23]. Forced vital capacity (FVC) and FEV1 were calculated as \% predicted values based on the Third National Health and Nutrition Examination Survey (NHANES III) equations for Caucasians [24]. Data from the 33 BOLD sites that had completed datasets at the time of writing were used for analyses.

\section{Definitions}

Chronic bronchitis symptoms were defined as both cough and phlegm on most days for $\geqslant 3$ months each year for $\geqslant 2$ years using affirmative answers to all the following questions: "Do you usually cough when you don't have a cold?", "Are there months in which you cough on most days?", "Do you cough on most days for as much as 3 months each year?" and confirmation that cough lasts $\geqslant 2$ years in a question "For how many years have you had this cough?" plus affirmative answers to a series of similar questions on phlegm. Chronic airflow obstruction (CAO) was defined by a post-bronchodilator $\mathrm{FEV} 1 / \mathrm{FVC}$ ratio less than the lower limit of normal for age and sex, based on NHANES III equations for Caucasians. Among those meeting this criteria, we classified severity of disease based on post-bronchodilator FEV1, according to the Global Initiative for Chronic Obstructive Lung Disease spirometric classification (FEV 1 $\geqslant 80 \%$ pred, $50-<80 \%$ pred, $30-<50 \%$ pred and $<30 \%$ pred) [25]. The presence of other medical conditions was determined based on questionnaire data. Biomass fuel use was defined as self-reported ever use of coal, coke, wood, crop residues or dung for cooking or heating for $>6$ months. Dyspnoea was measured using the modified Medical Research Council (mMRC) dyspnoea scale [26]. mMRC grade 2 ("dyspnoea when walking at own pace on the level") or higher was used to define clinically significant dyspnoea. Respiratory exacerbations were assessed based on the response to the question about "breathing problems that interfered with usual daily activities or caused the participant to miss work" and use of healthcare resources on the basis of self-reported breathing problems causing subjects to see a healthcare provider or be hospitalised. Quality of life was measured using the 12-item Short Form Health Survey (SF-12) questionnaire. Composite physical and mental health SF-12 scores were calculated and used for analyses. The summary scores range from 0 to 100, with 100 representing the best quality of life [27].

\section{Data analysis}

Apart from site-specific prevalence estimates, which were weighted to reflect the sampling design at each site, all other analyses used unweighted data. Factors associated with the presence of chronic bronchitis symptoms were examined by multiple logistic regression, with the following covariates as potential risk factors: age, sex, education, smoking status and exposure to passive smoke, occupational exposures to dust and fumes, biomass fuels use (use of coal, coke, wood, crop residues or dung for cooking or heating), comorbid conditions including other lung diseases (asthma, tuberculosis or lung cancer) and heart disease, 
family history of chronic lung diseases and hospitalisation for breathing problems prior to the age of 10 years. A similar model was applied, restricted to: 1) subjects with CAO, 2) subjects without CAO and 3) current smokers.

Linear regression models were applied to predict FEV1 and change in FEV1 after bronchodilator administration $(\triangle \mathrm{FEV} 1)$ as a function of chronic bronchitis symptoms and the covariates listed earlier. In addition, we applied separate logistic regression models to predict clinically significant dyspnoea, respiratory exacerbations, the use of healthcare resources and quality of life (lowest quartile) as a function of the same set of covariates as well as lung function data (CAO and FVC). These covariates were complemented with self-reported data on medical diagnoses of hypertension, diabetes and stroke in the analysis of the quality of life. These analyses were all performed in the cohort overall and separately in those with and without CAO. All regression models were adjusted for study site as a fixed effect, class variable.

Using the Wald Chi-squared statistic for site as a measure of the variability in prevalence of chronic bronchitis symptoms across sites, we used the reduction in this statistic after adjusting for covariates as a proxy for the proportion of overall site-to-site variability in chronic bronchitis prevalence that was attributable to the covariates.

Analyses were performed with $\mathrm{R}$ statistical software (version 3.3.1; www.R-project.org). Statistical significance refers to a $\mathrm{p}$-value $<0.05$.

\section{Results}

Prevalence of and potential risk factors for chronic bronchitis symptoms

Data from 23855 males and females from 33 BOLD study sites in 29 countries were analysed. The proportion of self-reported chronic bronchitis symptoms overall was 3.1\%: $3.6 \%$ for males and $2.6 \%$ for females. Chronic bronchitis symptoms were present in $10.2 \%$ of individuals with CAO and $2.2 \%$ of those without CAO (1.06\% and $1.97 \%$ of the total sample, respectively). Overall, proportion of subjects reporting chronic bronchitis symptoms increased with age, worse lung function and exposure to potential risk factors (table 1).

Figure 1 shows the weighted prevalence of chronic bronchitis symptoms by sex, site, smoking status and history of asthma. The prevalence of chronic bronchitis symptoms varied significantly across sites, with Lexington (KY, USA), Chui (Kyrgyzstan) and London (UK) having the highest rates (10.8\%, 8.3\% and $7.7 \%$, respectively) and Pune (India), Cotonou (Benin), Ile-Ife (Nigeria) and Blantyre (Malawi) each having a prevalence $<0.5 \%$. In all sites where prevalence of chronic bronchitis symptoms was $>1 \%$, they were reported by both individuals with and without CAO. $\sim 18 \%$ of the variance in the prevalence of chronic bronchitis symptoms between sites could be explained by the differences in the measured covariates.

In the multivariable analysis, factors significantly associated with an increased risk of reporting chronic bronchitis symptoms were older age, less education, current smoking, occupational exposure to fumes, a self-reported diagnosis of asthma or lung cancer and a family history of chronic lung disease (table 2). The potential risk factors profile was similar in subjects with and without $\mathrm{CAO}$, although there were no significant associations with either a family history of chronic lung disease or education in those without CAO. In an analysis restricted to current smokers, number of cigarettes smoked daily was an independent predictor of chronic bronchitis symptoms (for increase of 10 cigarettes per day OR 1.63, 95\% CI 1.37-2.00; $\mathrm{p}<0.001$ ).

\section{Burden associated with chronic bronchitis symptoms}

The presence of chronic bronchitis symptoms was related to worse lung function both in CAO and asthma groups as well as more pronounced response to bronchodilator administration (table 3). The proportion of subjects with improvement in $\mathrm{FEV}_{1} \geqslant 12 \%$ and $>200 \mathrm{~mL}$ after bronchodilator administration was similar in subjects with self-reported asthma and CAO ( $21.5 \%$ versus $21.8 \%, \mathrm{p}=0.820)$, while the proportion of those with FEV1 improvement of $>15 \%$ and $>400 \mathrm{~mL}$ was larger in the former group $(6.9 \%$ versus $5.3 \%, \mathrm{p}=0.039)$. The association of chronic bronchitis symptoms with worse lung function (FEV1 \% pred) was present after adjustment for potential confounders, both in the whole sample $(-2.74 \%, \mathrm{p}<0.001)$ and in subgroups of those with CAO $(-4.04 \%, \mathrm{p}<0.001)$ and without CAO $(-1.92 \%$, $\mathrm{p}<0.001)$. Similarly, the association of chronic bronchitis symptoms with increased FEV1 improvement after bronchodilator administration was independent from lung function (FEV1) and other potential confounders $\left(\triangle \mathrm{FEV}_{1} 17 \mathrm{~mL}, \mathrm{p}=0.011\right)$. In logistic regression analysis the presence of chronic bronchitis symptoms was associated with increased risk of other respiratory symptoms, respiratory exacerbations and reduced quality of life (table 4). After adjustment for possible confounders, the influence of chronic bronchitis symptoms on quality of life was significantly larger than that of asthma or CAO (SF-12 physical score -5.9 versus -4.9 versus -1.7 , respectively, $\mathrm{p}<0.001$; SF- 12 mental score -3.5 versus -1.4 versus -1.0 , respectively, $\mathrm{p}<0.001)$. 
TABLE 1 Basic characteristics of the study population

\begin{tabular}{|c|c|c|c|c|}
\hline & Proportion of population & CBS & OR $(95 \% \mathrm{Cl})$ & p-value \\
\hline Total $^{\#}$ & 100 & 3.1 & & \\
\hline \multicolumn{5}{|l|}{ Sex } \\
\hline Female & 52.5 & 2.6 & 1 & \multirow[t]{2}{*}{0.001} \\
\hline Male & 47.5 & 3.6 & $1.35(1.17-1.57)$ & \\
\hline \multicolumn{5}{|l|}{ Age years } \\
\hline $40-49$ & 36.5 & 2.2 & 1 & \multirow[t]{4}{*}{$<0.001$} \\
\hline $50-59$ & 31.1 & 3.2 & $1.49(1.23-1.80)$ & \\
\hline $60-69$ & 20.4 & 3.6 & $1.64(1.33-2.02)$ & \\
\hline$\geqslant 70$ & 12.0 & 4.3 & $2.01(1.60-2.53)$ & \\
\hline \multicolumn{5}{|l|}{ Education years } \\
\hline$>12$ & 22.7 & 2.5 & 1 & \multirow[t]{4}{*}{0.083} \\
\hline $6-12$ & 55.9 & 3.2 & $1.26(1.04-1.53)$ & \\
\hline$<6$ & 10.2 & 3.3 & $1.30(0.98-1.71)$ & \\
\hline None & 11.2 & 3.3 & $1.30(0.99-1.71)$ & \\
\hline \multicolumn{5}{|l|}{ Smoking status } \\
\hline Never-smoker & 59.8 & 1.8 & 1 & \multirow[t]{3}{*}{$<0.001$} \\
\hline Ex-smoker & 21.2 & 3.3 & $1.81(1.48-2.20)$ & \\
\hline Current smoker & 19.0 & 6.7 & $3.81(3.22-4.51)$ & \\
\hline \multicolumn{5}{|c|}{ Exposure to passive smoke } \\
\hline No & 78.5 & 2.8 & 1 & \multirow[t]{2}{*}{$<0.001$} \\
\hline Yes & 21.5 & 4.2 & $1.51(1.28-1.78)$ & \\
\hline \multicolumn{5}{|l|}{ Dusty job } \\
\hline No $(<1$ year) & 66.2 & 2.4 & 1 & \multirow[t]{2}{*}{$<0.001$} \\
\hline Yes & 33.8 & 4.4 & $1.89(1.63-2.19)$ & \\
\hline \multicolumn{5}{|c|}{ Occupational exposure to fumes } \\
\hline No & 90.7 & 3.0 & 1 & \multirow[t]{2}{*}{0.035} \\
\hline Yes & 9.3 & 3.8 & $1.28(1.02-1.62)$ & \\
\hline \multicolumn{5}{|l|}{ Biomass fuel use ${ }^{\pi}$} \\
\hline No & 34.9 & 2.9 & 1 & \multirow[t]{2}{*}{0.539} \\
\hline Yes & 65.1 & 3.0 & $1.05(0.89-1.25)$ & \\
\hline \multicolumn{5}{|c|}{ Chronic airway obstruction $\$$} \\
\hline $\mathrm{FEV}_{1} / \mathrm{FVC} \geqslant \mathrm{LLN}$ & 89.6 & 2.2 & 1 & \multirow[t]{5}{*}{$<0.001$} \\
\hline $\begin{array}{c}\mathrm{FEV}_{1} / \mathrm{FVC}<\mathrm{LLN} \text { and } \\
\mathrm{FEV}_{1} \geqslant 80 \% \text { pred }\end{array}$ & 3.0 & 4.8 & $2.20(1.54-3.14)$ & \\
\hline $\begin{array}{l}\mathrm{FEV}_{1} / \mathrm{FVC}<\mathrm{LLN} \text { and } \\
\text { FEV } 150-80 \% \text { pred }\end{array}$ & 5.3 & 10.1 & $4.93(4.03-6.05)$ & \\
\hline $\begin{array}{l}\mathrm{FEV}_{1} / \mathrm{FVC}<\mathrm{LLN} \text { and } \\
\mathrm{FEV}_{1} 30-50 \% \text { pred }\end{array}$ & 1.8 & 16.9 & $8.92(6.81-11.67)$ & \\
\hline $\begin{array}{l}\mathrm{FEV}_{1} / \mathrm{FVC}<\mathrm{LLN} \text { and } \\
\mathrm{FEV}_{1}<30 \% \text { pred }\end{array}$ & 0.3 & 23.7 & $13.57(7.93-23.12)$ & \\
\hline \multicolumn{5}{|l|}{ FVC } \\
\hline$\geqslant 80 \%$ pred & 68.4 & 2.9 & 1 & \multirow[t]{2}{*}{0.065} \\
\hline$<80 \%$ pred & 31.6 & 3.4 & $1.16(0.99-1.35)$ & \\
\hline \multicolumn{5}{|l|}{ Asthma } \\
\hline No & 94.5 & 2.3 & 1 & \multirow[t]{2}{*}{$<0.001$} \\
\hline Yes & 5.5 & 15.7 & $7.89(6.65-9.38)$ & \\
\hline Diagnosed heart disea & & & & \\
\hline No & 92.1 & 2.3 & 1 & 0.035 \\
\hline Yes & 7.9 & 3.4 & $1.46(1.03-2.08)$ & \\
\hline History of tuberculosis & & & & \\
\hline No & 97.3 & 3.0 & 1 & 0.001 \\
\hline Yes & 2.7 & 5.3 & $1.81(1.27-2.58)$ & \\
\hline
\end{tabular}

Data are presented as \%, unless otherwise stated. CBS: chronic bronchitis symptoms; FEV1: forced expiratory volume in $1 \mathrm{~s}$; FVC: forced vital capacity; LLN: lower limit of normal; \% pred: \% predicted. \#: $n=23855$; १: self-reported use of coal, coke, wood, crop residues or dung for cooking or heating; §: post-bronchodilator $\mathrm{FEV}_{1} / \mathrm{FVC}<\mathrm{LLN}$. 


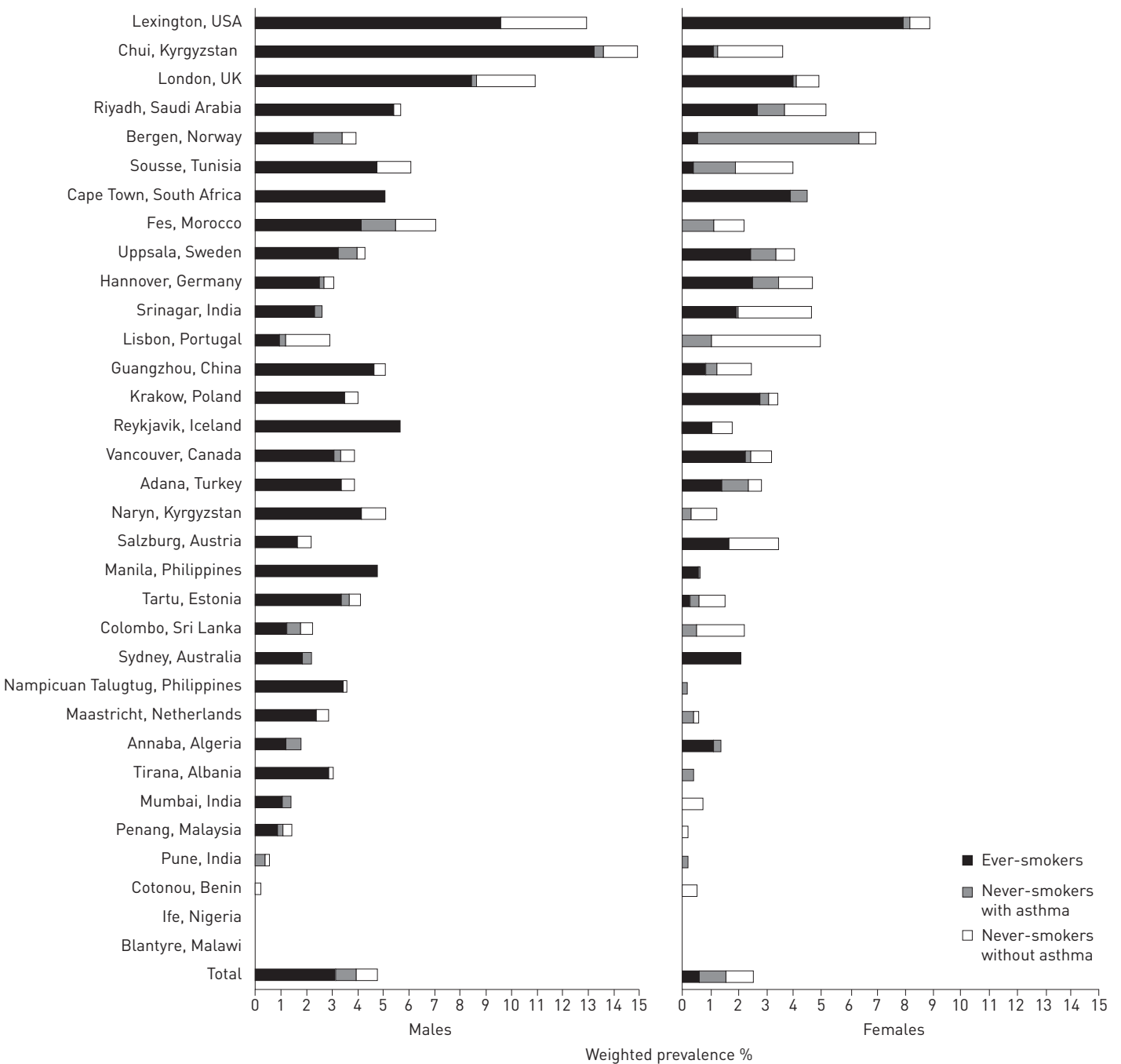

FIGURE 1 Estimated prevalence of chronic bronchitis symptoms across study sites.

TABLE 2 Predictors of chronic bronchitis symptoms in multivariable analysis

\begin{tabular}{lcc} 
& OR (95\% CI) & p-value \\
\hline Male sex & $1.25(0.91-1.71)$ & 0.163 \\
Age per 10-year increase & $1.39(1.22-1.58)$ & 0.001 \\
Education per 1-year increase & $0.97(0.94-0.99)$ & 0.031 \\
Smoking status & & \\
$\quad$ Past smoking & $1.12(0.76-1.68)$ & 0.557 \\
$\quad$ Current smoking & $2.74(1.94-3.87)$ & 0.001 \\
Exposure to passive smoke & $1.00(0.71-1.40)$ & 0.995 \\
Dusty job & $1.08(0.83-1.46)$ & 0.606 \\
Occupational exposure to fumes & $1.90(1.24-2.92)$ & 0.003 \\
Biomass fuel use & $0.52(0.16-1.71)$ & 0.282 \\
Current asthma (self-reported) & $7.9(5.73-10.91)$ & 0.001 \\
Diagnosed heart disease & $1.05(0.70-1.57)$ & 0.818 \\
Ever-diagnosed tuberculosis & $0.82(0.36-1.86)$ & 0.641 \\
Diagnosed lung cancer & $6.42(1.34-30.70)$ & 0.020 \\
Family history of chronic lung disease & $1.78(1.19-2.66)$ & 0.005 \\
Hospitalisation for breathing problems prior to the age of 10 years & $1.26(0.59-2.70)$ & 0.556 \\
\hline
\end{tabular}

Results based on logistic regression analysis with all of these variables and indicators for study site. 
TABLE 3 Lung function by the presence of chronic bronchitis symptoms, chronic airway obstruction (CAO) and self-reported asthma

\begin{tabular}{|c|c|c|c|c|c|c|c|c|c|}
\hline & \multicolumn{8}{|c|}{ Mutually exclusive categories } & \multirow[t]{2}{*}{ p-value $\#$} \\
\hline & Without CBS, CAO and asthma & CBS & CAO & CAO+CBS & Asthma & Asthma+CBS & CAO+asthma & $\mathrm{CAO}+$ asthma+CBS & \\
\hline Subjects $\mathrm{n}$ & 18551 & 345 & 1192 & 129 & 746 & 121 & 257 & 77 & \\
\hline FEV1 \% pred" & $89.7 \pm 17.1$ & $89.8 \pm 17.9$ & $66.6 \pm 19.8$ & $56.4 \pm 18$ & $86.6 \pm 16.4$ & $82.9 \pm 17.5$ & $59.8 \pm 18.3$ & $55.8 \pm 21$ & $<0.001$ \\
\hline FVC \% pred" & $88.1 \pm 16.8$ & $90.3 \pm 18$ & $86.5 \pm 21.8$ & $81.4 \pm 18.8$ & $86.8 \pm 16$ & $84.3 \pm 17.9$ & $82.6 \pm 20.1$ & $79.2 \pm 20.5$ & $<0.001$ \\
\hline $\mathrm{FEV}_{1} / \mathrm{FVC}^{\pi}$ & $79.4 \pm 6.0$ & $77.0 \pm 6.4$ & $58.4 \pm 8.8$ & $52.3 \pm 11$ & $78.1 \pm 6.2$ & $76.8 \pm 6.5$ & $55.5 \pm 10.6$ & $53.2 \pm 11.4$ & $<0.001$ \\
\hline$\Delta \mathrm{FEV} 1^{\pi} \mathrm{mL}$ & $67.9 \pm 14.2$ & $93.7 \pm 184.5$ & $110.2 \pm 171.0$ & $131.0 \pm 141.1$ & $113.9 \pm 176.7$ & $127.8 \pm 192.8$ & $177.3 \pm 184.7$ & $154.9 \pm 169.4$ & $<0.001$ \\
\hline $\begin{array}{l}\Delta \mathrm{FEV} 1^{\uparrow} \% \\
\text { of initial value }\end{array}$ & $3.1 \pm 7.0$ & $4.0 \pm 7.5$ & $7.9 \pm 12.4$ & $10.8 \pm 12.3$ & $5.6 \pm 9.0$ & $6.7 \pm 10.3$ & $14 \pm 15.3$ & $13.1 \pm 13.2$ & $<0.001$ \\
\hline $\begin{array}{l}\text { Proportion of subjects with } \Delta \mathrm{FEV}_{1}{ }^{\pi} \geqslant 12 \% \\
\text { and }>200 \mathrm{~mL}^{+}\end{array}$ & 5.3 & 9.3 & 18.6 & 30.2 & 13.5 & 19.0 & 38.9 & 32.5 & $<0.001$ \\
\hline $\begin{array}{l}\text { Proportion of subjects with } \Delta \mathrm{FEV} 1^{\pi}>15 \% \\
\text { and }>400 \mathrm{~mL}^{+}\end{array}$ & 1.4 & 2.0 & 4.1 & 3.9 & 4.6 & 5.0 & 11.7 & 6.5 & $<0.001$ \\
\hline
\end{tabular}




\begin{tabular}{|c|c|c|c|}
\hline & Total study sample & $\mathrm{CAO}^{+}$ & $\mathrm{CAO}^{-}$ \\
\hline \multicolumn{4}{|l|}{$\begin{array}{l}\text { mMRC dyspnoea scale } \geqslant 2 \\
\text { Respiratory exacerbations }\end{array}$} \\
\hline $\begin{array}{l}\text { Breathing problems interfering with daily } \\
\text { activities or causing subject to miss work } \\
\text { in the previous year }\end{array}$ & $4.28(3.07-5.95)$ & $5.66(3.08-10.41)$ & $3.66(2.41-5.55)$ \\
\hline $\begin{array}{l}\text { Breathing problems causing subject to } \\
\text { see a healthcare provider in the } \\
\text { previous year }\end{array}$ & $4.93(3.28-7.41)$ & $3.93(2.00-7.72)$ & $5.21(3.06-8.88)$ \\
\hline $\begin{array}{l}\text { Hospitalisation for breathing } \\
\text { problems in the previous year }\end{array}$ & $4.86(2.67-8.82)$ & $4.54(1.98-10.44)$ & $4.18(1.65-10.59)$ \\
\hline \multicolumn{4}{|l|}{ Quality of life } \\
\hline SF-12 mental score (lowest quartile) & $2.06(1.52-2.77)$ & $4.04(2.30-7.08)$ & $1.59(1.10-2.30)$ \\
\hline SF-12 physical score (lowest quartile) & $4.00(2.89-5.53)$ & $5.43(2.88-10.26)$ & $3.34(2.26-4.95)$ \\
\hline \multicolumn{4}{|c|}{$\begin{array}{l}\text { Data are presented as OR ( } 95 \% \text { Cl). Results adjusted for study site, age, sex, education, smoking status and } \\
\text { exposure to passive smoke, occupational exposures to dust and fumes, biomass fuels use, asthma, } \\
\text { tuberculosis, lung cancer, heart disease, chronic airway obstruction (CAO) (in the total study sample) and } \\
\text { forced vital capacity, plus data on hypertension, diabetes and stroke in the analysis of the quality of life. } \\
\text { mMRC: modified Medical Research Council; SF-12: 12-item Short Form Health Survey. }\end{array}$} \\
\hline
\end{tabular}

\section{Discussion}

We observed that prevalence of chronic bronchitis symptoms varied widely across the studied sites. More importantly, we have demonstrated that presence of chronic bronchitis symptoms is associated with a significant burden in affected individuals whether or not they have concurrent airflow obstruction, as evidenced by the associations with worse lung function and increased likelihood of dyspnoea, respiratory exacerbations and decreased quality of life.

Chronic bronchitis symptoms prevalence data from most, but not all studied sites are in the range of the previously published results based on questionnaires assessing symptoms [2-7]. Surprisingly, we have identified a few centres where only single subjects $(0-0.5 \%)$ reported chronic bronchitis symptoms. In addition, in these centres (Pune, India; Cotonou, Benin; Ile-Ife, Nigeria; and Blantyre, Malawi) the proportions of subjects who reported cough and who reported sputum production were lower in comparison to other sites. This observation is supported by some $[4,29,30]$, but not all studies from these countries [31]. More local data are needed to verify whether this is a reporting issue or if chronic productive cough is indeed rare in these populations, but the observations are consistent with the low prevalence of smoking and asthma in these populations. The magnitude of differences in prevalence of chronic bronchitis symptoms across sites reported here is large, but similar to that described in a younger population by the only other published study using standardised methods in different regions of the world [2]. Only $18 \%$ of the variance in the prevalence of chronic bronchitis symptoms between sites could be explained by variations across sites in the measured covariates. Part of this discrepancy may be due to limitations of the BOLD questionnaire, which does not ask questions about some potential risk factors, such as chronic rhinosinusitis and gastro-oesophageal reflux. Differences in the stigma associated with respiratory symptoms and the likelihood of reporting them are also probably important considerations.

The association between smoking and chronic bronchitis is well known $[2,18,20]$ and, in our data, holds for current but not ex-smokers (consistent with reports demonstrating that chronic bronchitis symptoms disappear after smoking cessation $[32,33]$ ). The association with a family history of chronic lung disease may be partially mediated by an increased risk of chronic bronchitis symptoms in asthma, but the effect shown in table 2 is at least partially independent of a personal history of asthma, and a genetic trait related with chronic bronchitis has also been reported [34].

We have described the wide spectrum of the negative outcomes (worse lung function, worse quality of life, more symptoms and more exacerbations) related to chronic bronchitis symptoms. Previous studies are concordant in reporting worse health status of chronic bronchitis subjects both in those with CAO and in those with normal lung function $[4,9,10,35,36]$. Similarly, in patients with asthma the presence of chronic cough and phlegm production has been associated with increased risk of uncontrolled asthma [37]. Of note, the adverse influence of chronic bronchitis on quality of life is probably larger than that of asthma or COPD, which confirms previously published results [38]. Despite associations of chronic bronchitis with airflow 
obstruction, negative outcomes from chronic bronchitis symptoms are also evident in individuals without airway obstruction. In our sample the number of these subjects was almost double that of chronic bronchitis subjects with CAO. For this group, chronic bronchitis has received surprisingly little attention outside epidemiological studies. There is a high prevalence of chronic airflow obstruction in those with the symptoms of chronic bronchitis and this is true in both smokers and never-smokers, and chronic bronchitis is a better predictor of future obstruction than the presence of dyspnoea [38]. The main limitation in using this information for COPD case finding is that this association is greatest for those with persistent symptoms, and symptoms are highly variable $[39,40]$. However, evidence for significant chronic bronchitis burden together with data demonstrating that chronic bronchitis symptoms may disappear after smoking cessation suggest that identification of these subjects and interventions aiming at smoking cessation may be of potential benefit.

In addition, we observed the association of chronic bronchitis symptoms with increased response to bronchodilator. The bronchodilator test is commonly used in differential diagnosis of asthma and COPD; however, is not an ideal tool because significant improvement is present in a substantial proportion of patients with both of these diseases [41]. When applying Global Initiative for Asthma (GINA) criteria for significant bronchodilator response to our population, the lower threshold in particular (FEV1 improvement of $\geqslant 12 \%$ and $200 \mathrm{~mL}$ ) was of little value. Interestingly, in our sample the presence of chronic bronchitis symptoms was related to a more pronounced response to bronchodilator both in CAO and asthma groups and after the exclusion of chronic bronchitis subjects absolute improvement after bronchodilator was similar in asthma and CAO. Differential diagnosis of asthma and COPD is often troublesome, with 15-45\% of subjects having the features of both of these diseases [42]. Chronic bronchitis symptoms have a significant impact on lung function/bronchodilator response, quality of life and probably prognosis, and the inclusion of these symptoms in classification of obstructive airway diseases could lead to more precise categorisation.

This study has some limitations. The cross-sectional survey design precludes assessment of causality. Data on chronic bronchitis and other respiratory symptoms are self-reported and thus prone to recall bias or to a culturally defined understanding of the symptoms being assessed. Similarly, data on asthma diagnoses are self-reported; observed lack of significant differences in response to bronchodilator between asthma and $\mathrm{CAO}$ groups could be due to this issue, at least partially, and underlines the low precision of self-reported asthma diagnoses. Questionnaire-based prevalence rates of chronic bronchitis symptoms are overestimated, because chronic cough and sputum production in some subjects are caused by asthma, bronchiectasis, gastro-oesophageal reflux, heart failure or chronic rhinosinusitis (post-nasal drip) [43]. In our study, asthma was reported by approximately one-third of those with chronic bronchitis symptoms. However, a large proportion of subjects who are troubled by chronic productive cough may not answer positively to all questions defining chronic bronchitis. In our sample, $\sim 11 \%$ of subjects reported that they "usually" cough and produce phlegm "when [they] don't have a cold" (compared with $\sim 3 \%$ reporting chronic bronchitis). How the questionnaire is understood in different settings will be influenced by language and local cultural differences [44,45], and even small changes in phrasing of a question can influence the estimates of respiratory symptoms [46]. The use of standardised questionnaires with strict quality control (including verifying the back-translations into each local language) and using trained staff to administer the questionnaires minimised, but could not eliminate the bias caused by such issues. However, there is a clear association between the prevalence of chronic bronchitis symptoms and the prevalence of smoking, suggesting that these responses to the questionnaire are relatively consistent. Finally, a dose of $200 \mu \mathrm{g}$ of salbutamol will not produce maximum bronchodilation in all participants, and in clinics a dose of $400 \mu \mathrm{g}$ is commonly recommended. The BOLD programme has used $200 \mu \mathrm{g}$ for both ethical and pragmatic reasons. Participants in the study, unlike clinic patients, have not asked for help with a specific problem, are less likely to have taken a $\beta$-agonist before and will not be used to the temporary side-effects. Standardising the dose to $200 \mu \mathrm{g}$ provides valuable and standardised information, but interpretation of the results needs to consider that the bronchodilation may not always be maximal. Published studies have used different doses of salbutamol, and GINA guidelines mention doses in the $200-400 \mu \mathrm{g}$ range as appropriate.

In conclusion, the prevalence of chronic bronchitis symptoms varied widely across the studied sites and their presence was associated with significant negative outcomes, not only in obstructed subjects, but also in those without airflow obstruction.

\section{Acknowledgements}

The authors would like to acknowledge the contribution of the BOLD study collaborators: NanShan Zhong (principal investigator (PI)), Shengming Liu, Jiachun Lu, Pixin Ran, Dali Wang, Jingping Zheng and Yumin Zhou (Guangzhou Institute of Respiratory Diseases, Guangzhou Medical College, Guangzhou, China); Ali Kocabaș (PI), Attila Hancioglu, Ismail Hanta, Sedat Kuleci, Ahmet Sinan Turkyilmaz, Sema Umut and Turgay Unalan (Cukurova University School of Medicine, Department of Chest Diseases, Adana, Turkey); Michael Studnicka (PI), Torkil Dawes, Bernd Lamprecht and Lea Schirhofer (Paracelsus Medical University, Department of Pulmonary Medicine, Salzburg, Austria); Eric Bateman (PI), Anamika Jithoo (PI), Desiree Adams, Edward Barnes, Jasper Freeman, Anton Hayes, Sipho Hlengwa, Christine Johannisen, Mariana Koopman, Innocentia Louw, Ina Ludick, Alta Olckers, Johanna Ryck and Janita Storbeck 
(University of Cape Town Lung Institute, Cape Town, South Africa); Thorarinn Gislason (PI), Bryndis Benedikdtsdottir, Kristin Jörundsdottir, Lovisa Gudmundsdottir, Sigrun Gudmundsdottir and Gunnar Gundmundsson (Dept of Allergy, Respiratory Medicine and Sleep, Landspitali University Hospital, Reykjavik, Iceland); Ewa Nizankowska-Mogilnicka (PI), Jakub Frey, Rafal Harat, Filip Mejza, Pawel Nastalek, Andrzej Pajak, Wojciech Skucha, Andrzej Szczeklik and Magda Twardowska (Division of Pulmonary Diseases, Department of Medicine, Jagiellonian University Medical College, Krakow, Poland); Tobias Welte (PI), Isabelle Bodemann, Henning Geldmacher and Alexandra Schweda-Linow (Hannover Medical School, Hannover, Germany); Amund Gulsvik (PI), Tina Endresen and Lene Svendsen (Department of Thoracic Medicine, Institute of Medicine, University of Bergen, Bergen, Norway); Wan C. Tan (PI) and Wen Wang (iCapture Center for Cardiovascular and Pulmonary Research, University of British Columbia, Vancouver, BC, Canada); David M. Mannino (PI), John Cain, Rebecca Copeland, Dana Hazen and Jennifer Methvin (University of Kentucky, Lexington, KY, USA); Renato B. Dantes (PI), Lourdes Amarillo, Lakan U. Berratio, Lenora C. Fernandez, Norberto A. Francisco, Gerard S. Garcia, Teresita S. de Guia, Luisito F. Idolor, Sullian S. Naval, Thessa Reyes, Camilo C. Roa, Jr, Ma. Flordeliza Sanchez and Leander P. Simpao (Philippine College of Chest Physicians, Manila, Philippines); Christine Jenkins (PI), Guy Marks (PI), Tessa Bird, Paola Espinel, Kate Hardaker and Brett Toelle (Woolcock Institute of Medical Research, Sydney, Australia), Peter G.J. Burney (PI), Caron Amor, James Potts, Michael Tumilty and Fiona McLean (National Heart and Lung Institute, Imperial College, London, UK); Emiel F.M. Wouters and Geert-Jan Wesseling (Maastricht University Medical Center, Maastricht, the Netherlands); Cristina Bárbara (PI), Fátima Rodrigues, Hermínia Dias, João Cardoso, João Almeida, Maria João Matos, Paula Simão, Moutinho Santos and Reis Ferreira (Portuguese Society of Pneumology, Lisbon, Portugal); Christer Janson (PI), Inga Sif Olafsdottir, Katarina Nisser, Ulrike Spetz-Nyström, Gunilla Hägg and Gun-Marie Lund (Department of Medical Sciences, Respiratory Medicine and Allergology, Uppsala University, Uppsala, Sweden); Rain Jõgi (PI), Hendrik Laja, Katrin Ulst, Vappu Zobel and Toomas-Julius Lill (Lung Clinic, Tartu University Hospital, Tartu, Estonia); Parvaiz A. Koul (PI), Sajjad Malik, Nissar A. Hakim and Umar Hafiz Khan (Sher-i-Kashmir Institute of Medical Sciences, Srinagar, India); Rohini Chowgule (PI), Vasant Shetye, Jonelle Raphael, Rosel Almeda, Mahesh Tawde, Rafiq Tadvi, Sunil Katkar, Milind Kadam, Rupesh Dhanawade and Umesh Ghurup (Indian Institute of Environmental Medicine, Mumbai, India); Imed Harrabi (PI), Myriam Denguezli, Zouhair Tabka, Hager Daldoul, Zaki Boukheroufa, Firas Chouikha and Wahbi Belhaj Khalifa (Faculté de Médecine, Sousse, Tunisia); Luisito F. Idolor (PI), Teresita S. de Guia, Norberto A. Francisco, Camilo C. Roa, Fernando G. Ayuyao, Cecil Z. Tady, Daniel T. Tan, Sylvia Banal-Yang, Vincent M. Balanag Jr, Maria Teresita N. Reyes and Renato. B. Dantes (Lung Centre of the Philippines, Philippine General Hospital, Nampicuan and Talugtug, Philippines); Sanjay Juvekar (PI), Siddhi Hirve, Somnath Sambhudas, Bharat Chaidhary, Meera Tambe, Savita Pingale, Arati Umap, Archana Umap, Nitin Shelar, Sampada Devchakke, Sharda Chaudhary, Suvarna Bondre, Savita Walke, Ashleshsa Gawhane, Anil Sapkal, Rupali Argade and Vijay Gaikwad (Vadu HDSS, KEM Hospital Research Centre Pune, Pune, India); Sundeep Salvi (PI), Bill Brashier, Jyoti Londhe and Sapna Madas (Chest Research Foundation, Pune, India); Mohamed C. Benjelloun (PI), Chakib Nejjari, Mohamed Elbiaze and Karima El Rhazi (Laboratoire d'Epidémiologie, Recherche Clinique et Santé Communautaire, Fès, Morroco); Daniel Obaseki (PI), Gregory Erhabor, Olayemi Awopeju and Olufemi Adewole (Obafemi Awolowo University, Ile-Ife, Nigeria); Mohamed Al Ghobain (PI), Hassan Alorainy (PI), Esam El-Hamad, Mohamed Al Hajjaj, Ayan Hashi, Rowena Dela, Rofel Fanuncio, Elizabeth Doloriel, Imelda Marciano, Lyla Safia (Saudi Thoracic Society, Saudi Arabia); Talant M. Sooronbaev (PI), Bermet M. Estebesova, Meerim Akmatalieva, Saadat Usenbaeva, Jypara Kydyrova, Eliza Bostonova, Ulan Sheraliev, Nuridin Marajapov, Nurgul Toktogulova, Berik Emilov, Toktogul Azilova, Gulnara Beishekeeva, Nasyikat Dononbaeva and Aijamal Tabyshova (Pulmunology and Allergology Department, National Centre of Cardiology and Internal Medicine, Bishkek, Kyrgyzstan); Kevin Mortimer (PI), Wezzie Nyapigoti, Ernest Mwangoka, Mayamiko Kambwili, Martha Chipeta, Gloria Banda, Suzgo Mkandawire and Justice Banda (The Malawi Liverpool Wellcome Trust, Blantyre, Malawi); Hasan Hafizi (PI), Anila Aliko, Donika Bardhi, Holta Tafa, Natasha Thanasi, Arian Mezini, Alma Teferici, Dafina Todri, Jolanda Nikolla and Rezarta Kazasi (Tirana University Hospital Shefqet Ndroqi, Tirana, Albania); Hamid Hacene Cherkaski (PI), Amira Bengrait, Tabarek Haddad, Ibtissem Zgaoula, Maamar Ghit, Abdelhamid Roubhia, Soumaya Boudra, Feryal Atoui, Randa Yakoubi, Rachid Benali, Abdelghani Bencheikh and Nadia Ait-Khaled (Faculté de Médecine Annaba, SEMEP, El Hadjar, Algeria); Li-Cher Loh (PI), Abdul Rashid and Siti Sholehah (Penang Medical College, Penang, Malaysia); and Herve Lawin (PI), Arsene Kpangon, Karl Kpossou, Gildas Agodokpessi, Paul Ayelo and Benjamin Fayomi (Unit of Teaching and Research in Occupational and Environmental Health, Cotonou, Benin).

\section{References}

1 Definition and classification of chronic bronchitis for clinical and epidemiological purposes. A report to the Medical Research Council by their Committee on the Aetiology of Chronic Bronchitis. Lancet 1965; 1: 775-779.

2 Cerveri I, Accordini S, Verlato G, et al. Variations in the prevalence across countries of chronic bronchitis and smoking habits in young adults. Eur Respir J 2001; 18: 85-92.

3 Lu M, Yao W, Zhong N, et al. Chronic obstructive pulmonary disease in the absence of chronic bronchitis in China. Respirology 2010; 15: 1072-1078.

4 de Oca MM, Halbert RJ, Lopez MV, et al. The chronic bronchitis phenotype in subjects with and without COPD: the PLATINO study. Eur Respir J 2012; 40: 28-36.

5 Jindal SK, Aggarwal AN, Gupta D, et al. Indian study on epidemiology of asthma, respiratory symptoms and chronic bronchitis in adults (INSEARCH). Int J Tuberc Lung Dis 2012; 16: 1270-1277.

6 Ferré A, Fuhrman C, Zureik M, et al. Chronic bronchitis in the general population: influence of age, gender and socio-economic conditions. Respir Med 2012; 106: 467-471.

7 Huchon GJ, Vergnenègre A, Neukirch F, et al. Chronic bronchitis among French adults: high prevalence and underdiagnosis. Eur Respir J 2002; 20: 806-812.

8 Halbert RJ, Natoli JL, Gano A, et al. Global burden of COPD: systematic review and meta-analysis. Eur Respir J 2006; 28: 523-532.

9 Agusti A, Calverley PM, Celli B, et al. Characterisation of COPD heterogeneity in the ECLIPSE cohort. Respir Res 2010; 11: 122 .

10 Kim V, Han MK, Vance GB, et al. The chronic bronchitic phenotype of COPD: an analysis of the COPDGene Study. Chest 2011; 140: 626-633. 
11 Ekberg-Aronsson M, Pehrsson K, Nilsson JA, et al. Mortality in GOLD stages of COPD and its dependence on symptoms of chronic bronchitis. Respir Res 2005; 6: 98.

12 Stavem K, Sandvik L, Erikssen J. Can Global Initiative for Chronic Obstructive Lung Disease stage 0 provide prognostic information on long-term mortality in men? Chest 2006; 130: 318-325.

13 Vestbo J, Prescott E, Lange P. Association of chronic mucus hypersecretion with FEV1 decline and chronic obstructive pulmonary disease morbidity. Copenhagen City Heart Study Group. Am J Respir Crit Care Med 1996; 153: $1530-1535$.

14 Lange $\mathrm{P}$, Nyboe J, Appleyard M, et al. Relation of ventilatory impairment and of chronic mucus hypersecretion to mortality from obstructive lung disease and from all causes. Thorax 1990; 45: 579-585.

15 Guerra S, Sherrill DL, Venker C, et al. Chronic bronchitis before age 50 years predicts incident airflow limitation and mortality risk. Thorax 2009; 64: 894-900.

16 Fletcher C, Peto R. The natural history of chronic airflow obstruction. Br Med J 1977; 1: 1645-1648.

17 Peto R, Speizer FE, Cochrane AL, et al. The relevance in adults of air-flow obstruction, but not of mucus hypersecretion, to mortality from chronic lung disease. Results from 20 years of prospective observation. Am Rev Respir Dis 1983; 128: 491-500.

18 LeVan TD, Koh WP, Lee HP, et al. Vapor, dust, and smoke exposure in relation to adult-onset asthma and chronic respiratory symptoms: the Singapore Chinese Health Study. Am J Epidemiol 2006; 163: 1118-1128.

19 Doney B, Hnizdo E, Graziani M, et al. Occupational risk factors for COPD phenotypes in the Multi-Ethnic Study of Atherosclerosis (MESA) lung study. COPD 2014; 11: 368-380.

20 Ehrlich RI, White N, Norman R, et al. Predictors of chronic bronchitis in South African adults. Int J Tuberc Lung Dis 2004; 8: 369-376.

21 Cai Y, Schikowski T, Adam M, et al. Cross-sectional associations between air pollution and chronic bronchitis: an ESCAPE meta-analysis across five cohorts. Thorax 2014; 69: 1005-1014.

22 Buist AS, Vollmer WM, Sullivan SD, et al. The Burden of Obstructive Lung Disease Initiative (BOLD): rationale and design. COPD 2005; 2: 277-283.

23 Miller MR, Hankinson J, Brusasco V, et al. Standardisation of spirometry. Eur Respir J 2005; 26: 319-338.

24 Hankinson JL, Odencrantz JR, Fedan KB. Spirometric reference values from a sample of the general U.S population. Am J Respir Crit Care Med 1999; 159: 179-187.

25 Global Initiative for Chronic Obstructive Lung Disease. Global Strategy for the Diagnosis, Management, and Prevention of COPD. http://goldcopd.org/gold-2017-global-strategy-diagnosis-management-prevention-copd Date last accessed: February 1, 2017.

26 Task Group on Surveillance for Respiratory Hazards in the Occupational Setting, Brooks SM. Surveillance for respiratory hazards. ATS News 1982; 8: 12-16.

27 Gandek B, Ware JE, Aaronson NK, et al. Cross-validation of item selection and scoring for the SF-12 Health Survey in nine countries: results from the IQOLA Project. International Quality of Life Assessment. J Clin Epidemiol 1998; 51: 1171-1178.

28 Global Initiative for Asthma. Global Strategy for Asthma Management and Prevention, 2017. http://ginasthma.org/ 2017-gina-report-global-strategy-for-asthma-management-and-prevention/ Date last accessed: February 20, 2017.

29 Desalu OO, Salami AK, Fawibe AE. Prevalence of cough among adults in an urban community in Nigeria. West Afr J Med 2011; 30: 337-341.

30 Nliwasa M, MacPherson P, Mukaka M, et al. High mortality and prevalence of HIV and tuberculosis in adults with chronic cough in Malawi: a cohort study. Int J Tuberc Lung Dis 2016; 20: 202-210.

31 Desalu OO, Adekoya AO, Ampitan BA. Increased risk of respiratory symptoms and chronic bronchitis in women using biomass fuels in Nigeria. J Bras Pneumol 2010; 36: 441-446.

32 Allinson JP, Hardy R, Donaldson GC, et al. The presence of chronic mucus hypersecretion across adult life in relation to chronic obstructive pulmonary disease development. Am J Respir Crit Care Med 2016; 193: 662-672.

33 Brown CA, Crombie IK, Smith WC, et al. The impact of quitting smoking on symptoms of chronic bronchitis: results of the Scottish Heart Health Study. Thorax 1991; 46: 112-116.

34 Zhu G, Agusti A, Gulsvik A, et al. CTLA4 gene polymorphisms are associated with chronic bronchitis. Eur Respir J 2009; 34: 598-604.

35 Kanervisto M, Saarelainen S, Vasankari T, et al. COPD, chronic bronchitis and capacity for day-to-day activities: negative impact of illness on the health-related quality of life. Chron Respir Dis 2010; 7: 207-215.

36 Martinez $\mathrm{CH}$, Kim V, Chen $\mathrm{Y}$, et al. The clinical impact of non-obstructive chronic bronchitis in current and former smokers. Respir Med 2014; 108: 491-499.

37 Cazzoletti L, Corsico AG, Albicini F, et al. The course of asthma in young adults: a population-based nine-year follow-up on asthma remission and control. PLoS One 2014; 9: e86956.

38 Meek PM, Petersen H, Washko GR, et al. Chronic bronchitis is associated with worse symptoms and quality of life than chronic airflow obstruction. Chest 2015; 148: 408-416.

39 de Marco R, Accordini S, Cerveri I, et al. Incidence of chronic obstructive pulmonary disease in a cohort of young adults according to the presence of chronic cough and phlegm. Am J Respir Crit Care Med 2007; 175: 32-39.

40 Vestbo J, Lange P. Can GOLD stage 0 provide information of prognostic value in chronic obstructive pulmonary disease? Am J Respir Crit Care Med. 2002; 166: 329-332.

41 Kesten S, Rebuck AS. Is the short-term response to inhaled beta-adrenergic agonist sensitive or specific for distinguishing between asthma and COPD? Chest 1994; 105: 1042-1045.

42 Postma DS, Rabe KF. The asthma-COPD overlap syndrome. N Engl J Med 2015; 373: 1241-1249.

43 Corsico AG, Villani S, Zoia MC, et al. Chronic productive cough in young adults is very often due to chronic rhino-sinusitis. Monaldi Arch Chest Dis 2007; 67: 90-94.

44 Pasick RJ, Stewart SL, Bird JA, et al. Quality of data in multiethnic health surveys. Public Health Rep 2001; 116 : 223-243.

45 Hunt S, Bhopal R. Self reports in research with non-English speakers. BMJ 2003; 327: 352-353.

46 Brøgger JC, Bakke PS, Gulsvik A. Comparison of respiratory symptoms questionnaires. Int J Tuberc Lung Dis 2000; 4: 83-90 